\title{
Mechanical Properties of CoCr Dental-Prosthesis Restorations Made by Three Manufacturing Processes. Influence of the Microstructure and Topography
}

\author{
Roberto Padrós ${ }^{1}$, Miquel Punset ${ }^{2,3,4}$, Meritxell Molmeneu ${ }^{2,4}{ }^{\oplus}$, Aritza Brizuela Velasco $^{5}$, \\ Mariano Herrero-Climent ${ }^{6}$, Elisa Rupérez ${ }^{2}\left(\mathbb{D}\right.$ and Francisco Javier Gil ${ }^{7,8, *}$ \\ 1 Barcelona Dental Institute, 08034 Barcelona, Spain; robertopadros@hotmail.com \\ 2 Biomaterials, Biomechanics and Tissue Engineering group (BBT), Department of Materials Science and \\ Engineering, Universitat Politècnica de Catalunya (UPC), Av. Eduard Maristany 16, 08019 Barcelona, Spain; \\ miquel.punset@upc.edu (M.P.); meritxell.molmeneu@upc.edu (M.M.); elisa.ruperez@upc.edu (E.R.) \\ 3 UPC Innovation and Technology Center (CIT-UPC), Technical University of Catalonia (UPC), \\ C. Jordi Girona 3-1, 08034 Barcelona, Spain \\ 4 Barcelona Research Centre in Multiscale Science and Engineering, Technical University of Catalonia (UPC), \\ Av. Eduard Maristany, 10-14, 08019 Barcelona, Spain \\ 5 Department of Surgery and Medical-surgical Specialties, University of Oviedo, 33006 Oviedo, Spain; \\ aritzabrizuela@hotmail.com \\ 6 Porto Dental Institute, 4150-518 Porto, Portugal; dr.herrero@herrerocliment.com \\ 7 Bioengineering Institute of Technology, International University of Catalonia, Josep Trueta s/n, \\ 08195 Barcelona, Spain \\ 8 School of Dentistry, Faculty of Medicine and Health Science, Universitat Internacional de Catalunya (UIC), \\ C. Josep Trueta s/n, 08195 Sant Cugat del Vallès, Spain \\ * Correspondence: xavier.gil@uic.cat
}

Received: 11 May 2020; Accepted: 10 June 2020; Published: 14 June 2020

\begin{abstract}
The aim of this study is to compare the mechanical properties of three different dental restorations' manufacturing processes (CADCAM milling, casting and laser sintering) generated by only one laboratory scanner focusing on marginal fit analysis and their mechanical properties. A chrome-cobalt ( $\mathrm{Cr}-\mathrm{Co}$ ) alloy from the same batch was used for three different methods to make an implant abutment. This simulates a maxillary right first molar that was fixed in a hemi-maxillary stone model. Five scans were performed by each tested framework. Nine frameworks were manufactured for each manufacture procedure. Field-Emission Scanning Electron Microscope (FE-SEM) direct vision was used to marginal gap measurement in five critical points for each specimen. In order to fix the samples in the microscope chamber, the restorations were submitted at a compression load of $50 \mathrm{~N}$. The samples always have the same orientation and conditions. The resolution of the microscope is $4 \mathrm{~nm}$ and it is equipped by J image software. The microstructure of the samples was also determined with the FE-SEM equipped with EDS-microanalysis. Roughness parameters were measured using White Light Interferometry (WLI). The arithmetical mean for the $R_{a}$ and $R_{q}$ of each sample was calculated. The samples were mechanically characterized by means of microhardness and flexural testing. Servo-hydraulic testing machine was used with cross-head rate of $1 \mathrm{~mm} / \mathrm{min}$. Two-way ANOVA statistical analysis was performed to determine whether the marginal discrepancies and mechanical properties were significantly different between each group (significance level $p<0.05$ ). The overall mean marginal gap values were: from $50.53 \pm 10.30 \mu \mathrm{m}$ for the samples produced by CADCAM to $85.76 \pm 22.56 \mu \mathrm{m}$ for the samples produced by the casting method. Laser sintering presents a marginal gap of $60.95 \pm 20.66 \mu \mathrm{m}$. The results revealed a statistically significant difference $(p$-value $<0.005)$ in the mean marginal gap between the CADCAM systems studied. The higher flexure load to fracture for these restorations were for CADCAM restoration and the lower was for the casting samples. For these restorations, CADCAM Restoration yielded a higher flexure load to
\end{abstract}


fracture and Casting ones yielded the lower. Porosity and microstructure play a very important role in the mechanical properties.

Keywords: CADCAM milling; casting; laser sintering; additive manufacturing; marginal fit; Cr-Co alloy; dental prosthesis; dental restorations; mechanical properties; roughness; flexural load to fracture; hardness

\section{Introduction}

In the last decade, the dental restorative sector has probably undergone the biggest technological revolution throughout its history. The continuous appearance of new technologies in both digital and manufacturing industries has enabled continuous improvement throughout $\mathrm{R}+\mathrm{D}+\mathrm{I}$ in order to overcome the drawbacks of conventional manufacturing processes.

The aforementioned revolution of the manufacturing processes has been accompanied by a parallel digital technology revolution, along with also the near-immediate implementation of new-developed procedures based on digital technologies [1-5]. As a result, digital dentistry revolution involved rapid implementation of newly-developed technologies such as 3D-Imaging [3,6], computer-aided design (CAD) $[1,4,7,8]$, computer-aided manufacturing (CAM) $[9,10]$, intraoral scanning [3,6], cone-beam computer tomography (CBCT) [11-15], x-ray computer micro tomography $(\mu-C T)[16,17]$, and computer-aided implantology $[2,18]$, among the most relevant.

In summary, manufacturing processes have evolved over time from traditional methods, with a high-level handicraft production component based on classic conformation methods (casting, plastic deformation and subtractive methods), to automated computer-aided methods with a high degree of technical sophistication using leading-edge technologies. For this latter group of state-of-the-art processes, two main families of computer-aided processes must be highlighted, computer-aided design and milling subtractive systems (CADCAM) and computer-aided design and fabrication additive manufacturing methods (AM).

Digital dentistry is continually growing from the casting process, from the lost wax method for manufacturing frameworks for dental restorations, to the use of CADCAM technology. The evolution to digital processes avoids many mistakes and the dependence of the laboratory technician's ability [18-20]. The use of digital processes achieves better accuracy following the workflow stages: scanning, design and manufacturing. In recent years, new procedures and technologies, along with advanced new materials, have helped the introduction of new methodologies to produce dental restorations [1-5].

The combination of advanced technology in both digital techniques and automated computer-integrated manufacturing systems has led to a great leap forward in both oral implantology and dental restoration sectors also known in the field of dentistry as Digital Dentistry or Dentistry 3.0 [10]. As a result, there is a wide range of technologies currently available for $\mathrm{CoCr}$ dental restoration manufacturing. Some of them are based on subtractive manufacturing methods such as CADCAM milling (CADCAM) systems [7-10], and the rest of the ever-expanding remaining group of processes are based on additive manufacturing methods such as direct metal laser-sintering systems (DMLS) occasionally referred to as Selective Laser Sintering (SLS) or Selective Laser Melting (SLM) [21-23], Metal Injection Molding (MIM) [24], Electron Beam Melting (EOS) [25] and Laser Engineering Net Shaping (LENS) [26], among others.

The newly state-of-art implemented technologies would theoretically enable overcoming the intrinsic limitations of conventional manufacturing techniques (machining, casting, forge and pressing). Some of the more important limitations would include high tolerance, low adjustment and dimensional accuracy, limited capacity in the production of complex shapes and low volumes of production, consequently leading to high associated product manufacturing costs. 
For the long-term framework behavior perspective, it is very important to take into account some key-factors such as the quality of surface finishing, marginal accuracy, mechanical properties, corrosion resistance, ion-release behavior, and of course biocompatibility [27-31]. One of the most important aspects is the accuracy, the minimization of the gaps and high precision in the adjustment of the structures [32-41]. Discrepancies in the marginal fit can produce recurrent caries, plaque accumulation, periodontal diseases or fracture of the dental restoration [42-48].

Many researchers have been focusing their efforts on evaluating the gap size effect on dental restoration functional behavior in order to determine and finally set a gap critical-size acceptance limit value for clinical use. However, gap value strongly depends on both measuring and manufacturing methods used. Currently, there is no general consensus regarding an acceptable tolerance limit. As a result, a general consensus has not been found in the bibliographical surveys, which has revealed a high level of discrepancy in the range of 35 to $120 \mu \mathrm{m}[44,45,49]$. In the same way, with regards to accuracy, there is neither a specific limit value nor a general consensus amongst researchers in this area. Some works reported that the best results were yielded by the CADCAM systems, others by laser sintering or even through traditional casting techniques, while other authors did not find substantial differences between these systems [50,51]. The marginal fit has a key role in the dental restoration success and the new strategic objective (goal) would be focused on achieving a maximum gap value in the range of 25 to $50 \mu \mathrm{m}$ to ensure good behavior [5,52-54].

Different methodologies have been used to evaluate the marginal gaps and the fitting of prosthetic dental restorations over time, including optical microscopy [55], profile projector [10], micro-CT [13-15] or laser videography [30], with different results. For this research, the measurements have been realized by High Resolution Field Emission Scanning Electron Microscope (HR-FSEM), with more than 100 measures for each model. Samples were fixed and observed with the same position and orientation in all cases. The same batch of the CoCr alloy avoids the influence of the different materials tested on the results. Furthermore, the flexure load to fracture of $\mathrm{CoCr}$ frameworks has been also determined for all manufacturing methods evaluated, and the influence of the marginal fit and the microstructure were also studied/evaluated. Furthermore, the originality of this contribution is also the determination of the influence of the microstructure of the material obtained by each manufacturing process on the mechanical properties, surface quality and the defects of the prosthesis.

\section{Materials and Methods}

\subsection{Model Preparation}

A master model was obtained from a real clinical situation: the replacement of an absent (pontic) tooth (FDI $\left.n^{\circ} 15\right)$ with the construction of a fixed partial denture on natural abutments (FDI $n^{\circ} 14$ and 16) with three elements.

The natural teeth were prepared with a $1.2 \mathrm{~mm}$ deep $90^{\circ}$ finish line around the contour of the abutments $\left(360^{\circ}\right)$, with a convergence angle of the walls of approximately $10^{\circ}$. The termination line, being natural teeth, was more apical in the vestibular and palatar areas.

An impression of abutment teeth was made using an addition silicone 3M Express tm 2 Penta with double viscosity (3M, Saint Paul, MN, USA). The impression was poured to obtain a master cast using Diemet-E epoxy resin (Erkodent ${ }^{\mathrm{TM}}$ Erich Kopp, Pfalzgrafenweiler, Germany). Subsequently, the master cast was duplicated, obtaining 18 working models.

Duplication procedures were performed in a room with humidity and temperature conditions within the following limits: $70-80 \%$ and $23-25{ }^{\circ} \mathrm{C}$, respectively. All the models were made in Diemet-E epoxy resin by the same operator and following the same working sequence protocol from a silicon index key Wirosil ${ }^{\mathrm{TM}}$ Duplicating Silicone (BEGO Herbst GmbH \& Co, Bremen, Germany) and respecting the manufacturer's instructions. The procedure was repeated until 18 models free of pores and imperfections were obtained. 


\subsection{Study Groups Assignment}

The models were divided in three groups:

- Group A: Cr-Co frameworks manufactured using wax-lost casting method. A total of nine models were performed $(n=9)$;

- Group B: Cr-Co frameworks manufactured using a 5-axis CADCAM milling system. A total of nine models were performed $(n=9)$;

- Group C: Cr-Co frameworks manufactured using Laser Sintering system. A total of nine models were performed $(n=9)$.

\subsection{Structure Design and CADCAM Manufacturing}

Models were digitalized using a desktop optical scanner Imetric (Imetric 3D SA, Geneva, Switzerland)) in a dental laboratory (Archimedes Pro ${ }^{\mathrm{TM}}$, La Seu d'Urgell, Spain). Structures were computer-designed using specific software for prosthodontic design Exocad ${ }^{\mathrm{TM}}$ (Exocad GmbH, Darmstadt, Germany) respecting the following specifications:

- Thickness of $0.5 \mathrm{~mm}$ around the entire outline of the structure;

- Pontic in FDP position $\left(\mathrm{n}^{\circ} 15\right)$ with a convex shape on its cervical surface and $1 \mathrm{~mm}$ away from the edentulous crest;

- Application of a space of $50 \mu \mathrm{m}$ on the dies to $1 \mathrm{~mm}$ form the location of the finishing line.

Nine samples $(\mathrm{n}=9)$ were manufactured by CADCAM system using 5-axis Zfx-Sauer-10 milling cutter unit machine (Zimmer, Dachau, Germany), nine samples $(n=10)$ were manufactured by means of casting using lost-wax technique with coating of phosphate and nine were manufactured by laser sintering method using a DLMS machine EOSINT M270 (EOS, Munich, Germany). The feedstock CoCr powder material used was powder with particle size in the range from 0.01 to $0.1 \mathrm{~mm}$ in diameter. Samples were verified in terms of both dimensions and volume of the structure.

These frameworks were not cemented. All structures were made of $\mathrm{Cr}$-Co alloy (Dentaurum Gmbh\&Co, Ispringer, Germany) (Figure 1) with the same chemical composition in all cases, which was determined by energy dispersive $\mathrm{x}$-ray spectroscopy (EDS) microanalysis. Co $\mathrm{Cr}$ alloys are the most used in the dental restorations. One of the most interesting properties of this alloy is its wide melting temperature range that avoids distortion in the structures. The chemical composition in weight percentage is shown in Table 1.

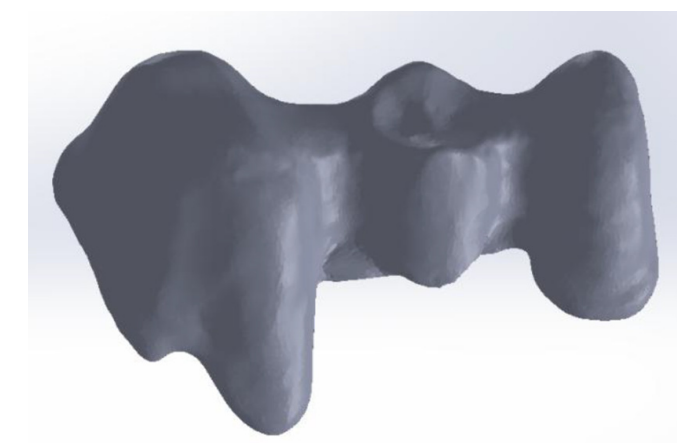

Figure 1. 3D-CAD model of CoCr dental restoration evaluated.

Table 1. Chemical composition of CoCr alloy ( $w \mathrm{t} \%)$.

\begin{tabular}{ccccccc}
\hline Chemical Element & Co & Cr & W & Si & C & Nb \\
\hline (wt $\%)$ & $56.53 \pm 2.11$ & $27.11 \pm 1.31$ & $9.64 \pm 0.79$ & $1.27 \pm 0.80$ & $<1 \%$ & $<1.5 \%$ \\
\hline
\end{tabular}


The size of the Co-Cr powder (Remanium Star CL, Dentaurum, Ispringen, Germany) was 10-40 $\mu \mathrm{m}$ in diameter with a coefficient of thermal expansion is $14.1 \times 10^{-6} \mathrm{~K}^{-1}$ and with a melting temperature around $1495^{\circ} \mathrm{C}[56]$.

\subsection{Surface Roughness}

Roughness measurements were made using non-contact White-Light (WLI) optical interferometry (Wyko NT1100 Optical Interferometer, Veeco Instruments, Plainview, NY, USA), in vertical scanning interferometry mode at $\times 10$ to $\times 100$ magnification. The interferometric technique is ideal for imaging these surfaces as a large area of the surface can be imaged with a high vertical resolution $(\approx 2 \mathrm{~nm})$. The analysis area was $63 \times 47 \mu \mathrm{m}$. Data filtering and analysis were performed with specific image analysis software (Wyko Vision 32; Veeco Instruments, Karlsruhe, Germany). A Gaussian filter was used to eliminate tilt from every surface analysis in order to separate waviness and form from roughness. The amplitude parameter (Sa) and the Index area (SA Index) were evaluated for three different specimens of each group of samples. Two samples of each type and four zones in each sample were analyzed. Ten roughness measures were obtained for each sample.

\subsection{Surface Morphology and Marginal Gap Determination.}

Surface morphology and composition were analyzed by means of high-resolution Field Emission Scanning Electron Microscopy (HR-FSEM) using a Neon 40 Surface Scanning Electron Focused Ion Beam Zeiss (Zeiss, Oberkochen, Germany) equipment with GEMINIS and Image-J software (Gemini2, Mol. Devices, San José, CA, USA) was used for dimensional measurement analysis.

In order to fix the sample in the microcopy chamber, the models were anchored with clamps and a $50 \mathrm{~N}$ load was applied to the middle of the model in order to ensure proper fixation. Load was always applied in the same position and direction to have exactly the same angle between the model and the electron beam. This load is applied in order to avoid micromovements which could affect the measurements. This load $(50 \mathrm{~N})$ does not produce plastic deformation or damage in the model. This method is according to the Holmes et al. and Affy et al. [57,58]. A scheme can be observed in Figure 2.
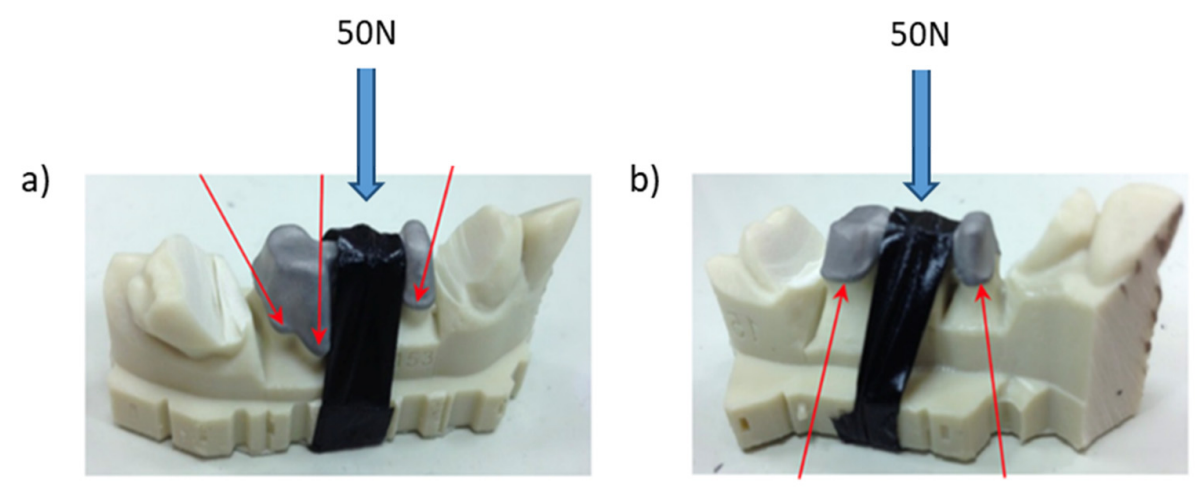

Figure 2. Images showing both interior and exterior regions of interest for accuracy measurement, as well as defining the point of load application and he direction of the applied load: (a) Outer region with three regions of interest and (b) Inner region with two regions of interest.

Gap discrepancies were determined in three areas of the vestibular regions as well as in two areas of the palatal regions, as can be observed in Figure 2. The points are random and these are taken every 1 micrometer to the right and to the left, up to a distance of $500 \mu \mathrm{m}$ from the point to the right and $500 \mu \mathrm{m}$ to the left. Therefore, for each point, 1000 measurements are taken. These distances and the operation distances are controlled by the software of the microscope. 


\subsection{Mechanical Testing}

Hardness distribution in a cross-section of specimens was measured using an Akashi Vickers microhardness tester model MVK-H0 (Akashi, Matsusawa, Japan) with a load of $1 \mathrm{Kgf}$ for a dwell loading time of $15 \mathrm{~s}$.

There is no international standard for measuring the flexural load to fracture on dental structures. For this reason, and according to the methods of other authors simulating the real case [59-61], 3-point bending tests were performed.

Mechanical testing grips have been precision engineered in order to be able to carry out the load application on the manufactured samples as close as possible to the real conditions [62]. In addition, mechanical grips have also been precision-designed and manufactured in order to ensure a perfect accommodation of samples during 3-point flexure tests. With regards to the starting material used for the manufacture of testing grips, a highly resistant refractory steel has been selected in order to avoid any deformation during mechanical tests. Samples were grip-fixed in a cantilever configuration. The load application was axially conducted by a pointed tool attached to an upper grip, which was perpendicularly aligned with the horizontal-axis of the framework, with a single point of contact located in the middle of the restoration (Figure 3b). The length of the clamp was $26 \mathrm{~mm}$ and the point where the load is applied was in the middle $(13 \mathrm{~mm})$ from the ends. Mechanical assays were performed using a universal servo-hydraulic testing machine, Bionix model 370 (MTS, Minneapolis, MN, USA) (Figure 3c) equipped with a load cell of $25 \mathrm{KN}$. The equipment was controlled by means of a PC interface using software TESTAR II ${ }^{\circledR}$ (MTS, Minneapolis, MN, USA). Mechanical tests were conducted using a constant cross-head rate of $1 \mathrm{~mm} / \mathrm{min}$ for all tests.
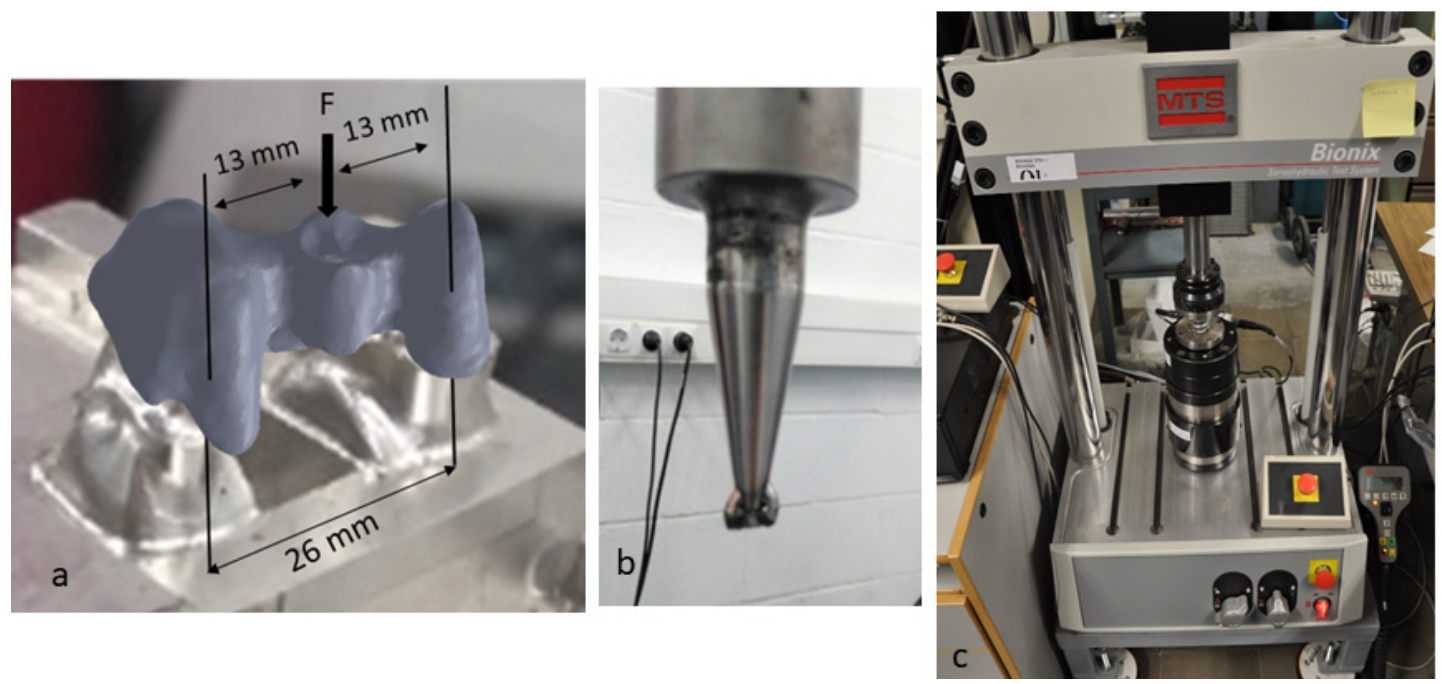

Figure 3. Overall 3-Point Flexure test set-up. (a) Lower clamp used for sample positioning, (b) Upper clamp used for load application, (c) MTS Bionix 370 Servo-hydraulic universal testing machine.

\subsection{Statistical Analysis}

Means and standard deviations in both Sa and SA Index surface topography parameters, as well as gap, were determined for all group of samples. T-Student and one-way ANOVA tests $(\alpha=0.005)$ were used to assess the influence of the manufacturing process on both the roughness parameters and gap. The differences were considered to be significant when $p<0.05$.

All statistical analyses were done with a statistical software package (Minitab release 13.0; Minitab Inc., Coventry, UK). 


\section{Results}

The SEM analysis of marginal gap performed in 135,000 measurements-i.e., 5000 measurements for each sample analyzed at a rate of 1000 measurements for each of the five areas of interest evaluated. Figure 4 shows examples of the different accuracy for three samples obtained by CADCAM, casting and laser sintering. Mean values for the CADCAM system studied. Figure 5 shows the different mean gap values (marginal fit) obtained by all manufacturing methods, which values are summarized in Table 2 . The results present statistical significance differences between the three different processes $(p<0.05)$.

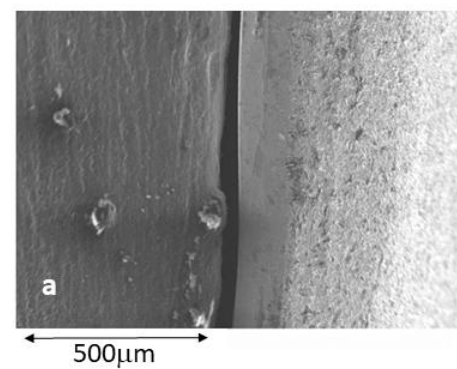

CADCAM

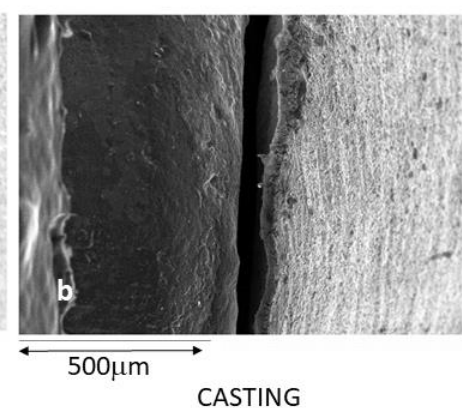

CASTING

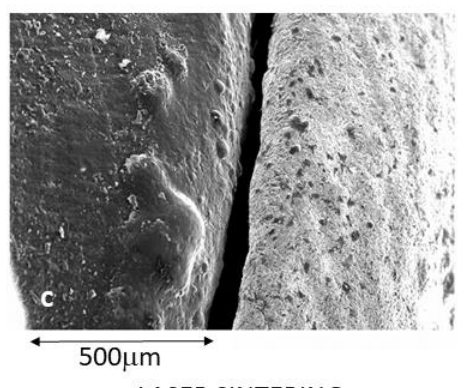

LASER SINTERING

Figure 4. SEM-Micrographs of discrepancy measurement obtained by different processes: (a) CADCAM, (b) Casting, (c) Laser sintering.

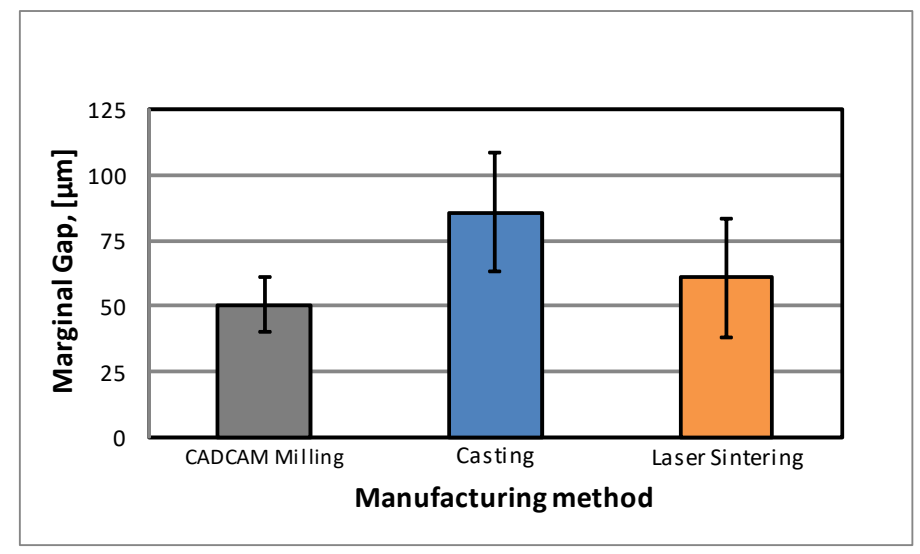

Figure 5. Marginal accuracy for the dental restoration manufactured by different methods.

Table 2. Marginal gap, roughness, hardness and mechanical properties test results.

\begin{tabular}{lccc}
\hline \multirow{2}{*}{ Properties/(Units) } & \multicolumn{2}{c}{ Manufacturing Process/Results (mean \pm STD) } \\
\cline { 2 - 4 } & CADCAM & Casting & Laser Sintering \\
\hline Marginal Gap, $(\boldsymbol{\mu m})$ & $50.53 \pm 10.30$ & $85.76 \pm 22.56$ & $60.95 \pm 20.66$ \\
\hline Sa, $(\mathbf{n m})$ & $731.27 \pm 19.0$ & $796.60 \pm 19.8$ & $859.5 \pm 18.9$ \\
\hline SA Index area & $2.1 \pm 0.1$ & $2.2 \pm 0.1$ & $1.8 \pm 0.1$ \\
\hline Hardness, (HV) & $356 \pm 20$ & $390 \pm 15$ & $473 \pm 25$ \\
\hline Flexural load to fracture, $(\mathbf{N})$ & $6813 \pm 169$ & $6291 \pm 105$ & $5422 \pm 302$ \\
\hline Deflection to fracture, $(\mathbf{m m})$ & $4.10 \pm 1.12$ & $2.55 \pm 1.21$ & $3.75 \pm 1.10$ \\
\hline
\end{tabular}

The mean values and the standard deviations of all properties evaluated (the Vickers hardness, marginal Gap, Surface roughness and area index, as well as flexure load and deflection to fracture) are summarized in Table 2.

Roughness measurements results confirmed the better surface finishing of CADCAM milled as compared with the rest of the evaluated processes, casting and laser sintering, as seen in Figure 6. 
As shown in Figure 6, the results of roughness measurements confirmed that CADCAM Milled had better surface finishings in comparison to the other evaluated processes (casting and laser sintering) Figure 7 shows the 3D topography maps of samples manufactured by all studied methods. These results have statistical significant differences between each manufacturing system.
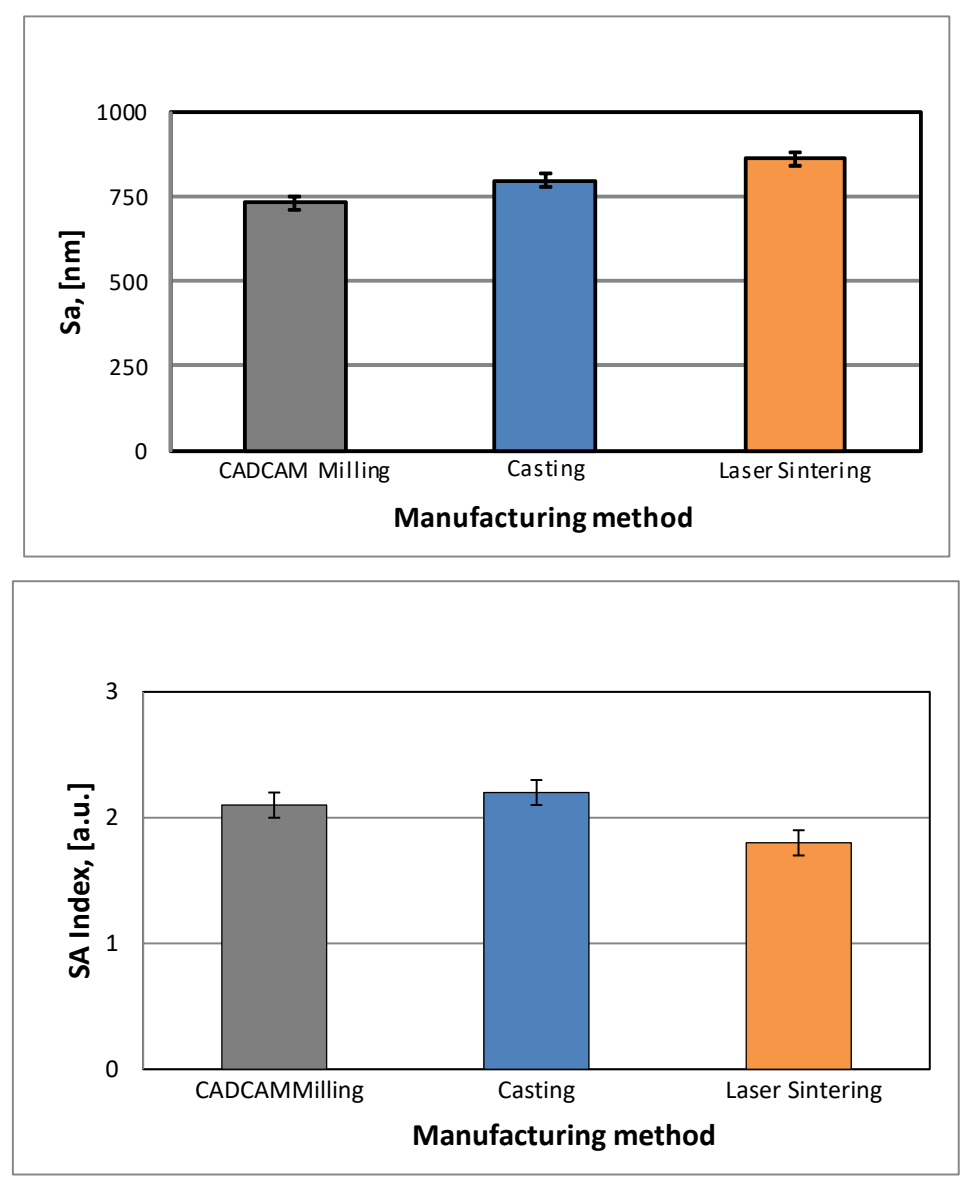

Figure 6. Results of roughness (Sa) and the surface area index for the different dental restorations.

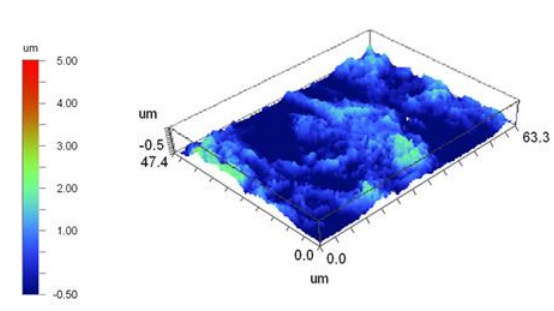

a. CASTING

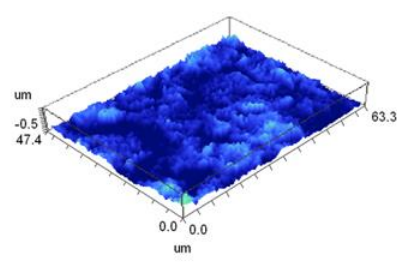

b. CADCAM

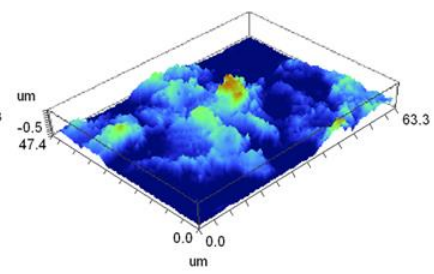

c. LASER SINTERING

Figure 7. 3D topographic maps of three different models obtained by the White Light Interferometry (WLI) method: (a) Casting, (b) CADCAM, and (c) Laser sintering.

The results of microhardness are shown in Figure 8. The results present statistical significance differences between them. 


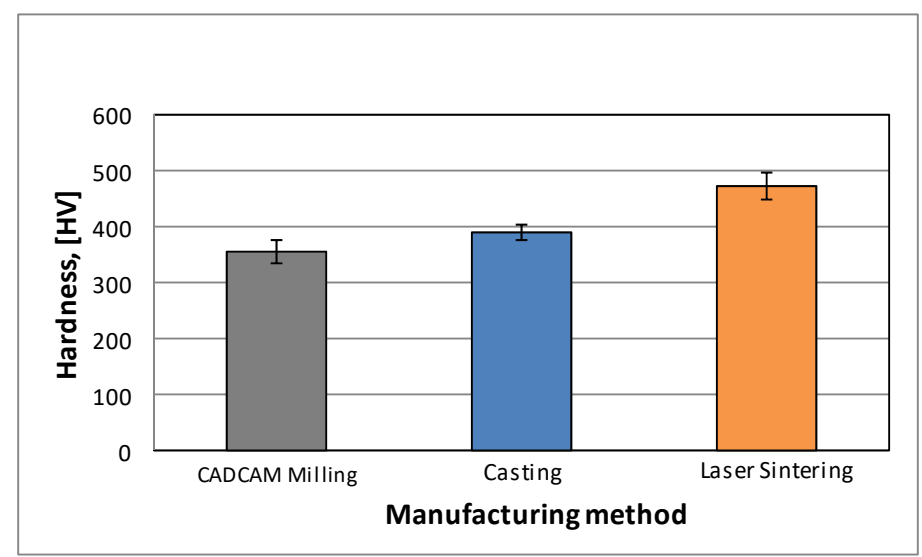

Figure 8. Microhardness (HVN) for the samples obtained with different methods.

Both flexural load to fracture and deflection to fracture results obtained for each fabrication method are shown in Figure 9. Flexural load to fracture presented statistically significant differences between them. The small standard deviations are indicative of the high degree of reproducibility achieved by all manufacturing methods. However, the same comparison in terms of deflection to fracture did not present statistically significant differences.
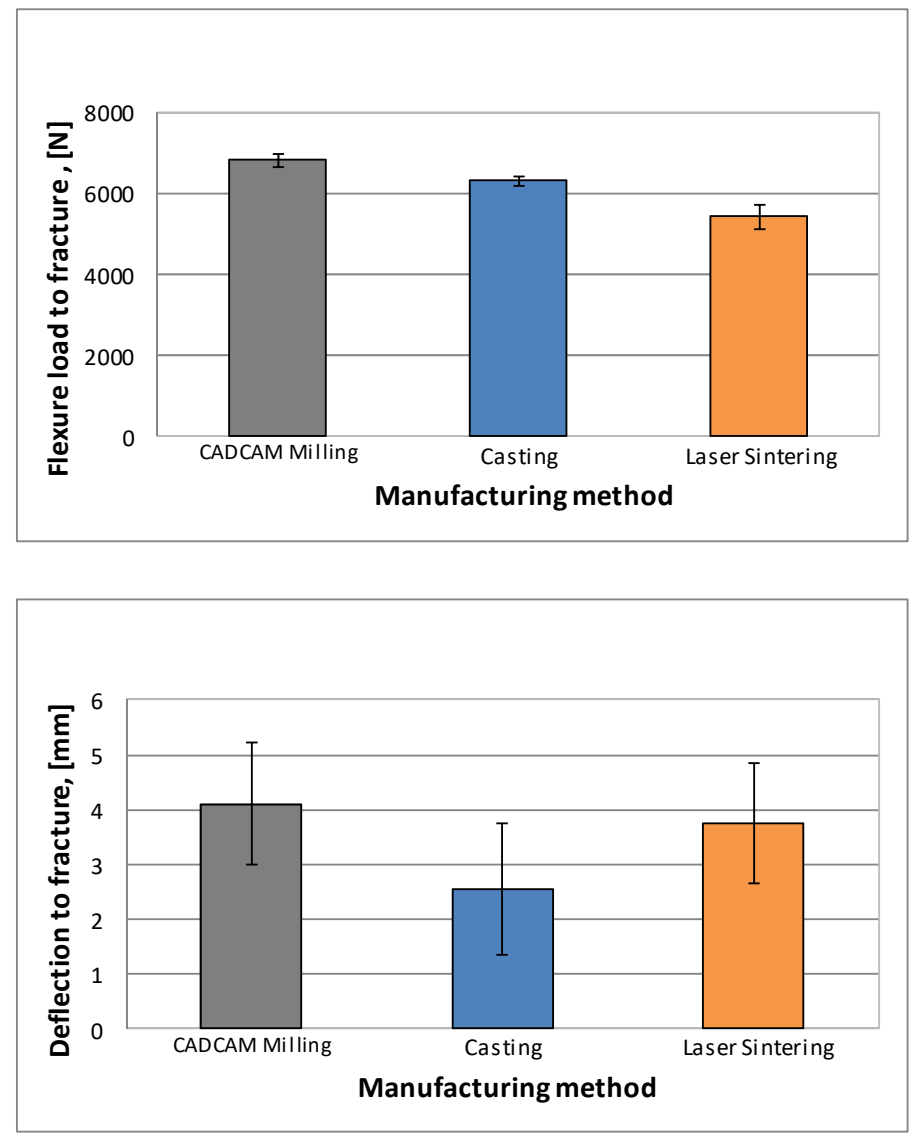

Figure 9. Flexural load to fracture and deflection to fracture obtained by three point bending for each dental restoration method.

The microstructural analysis of manufactured samples would explain the differences in the mechanical properties obtained. Figure 10a shows a sample obtained by CADCAM milling, we can observe the machining marks on the surface without porosity. 
a)

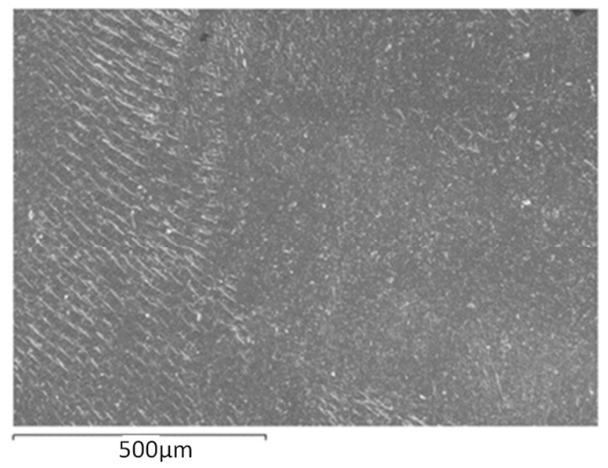

b)

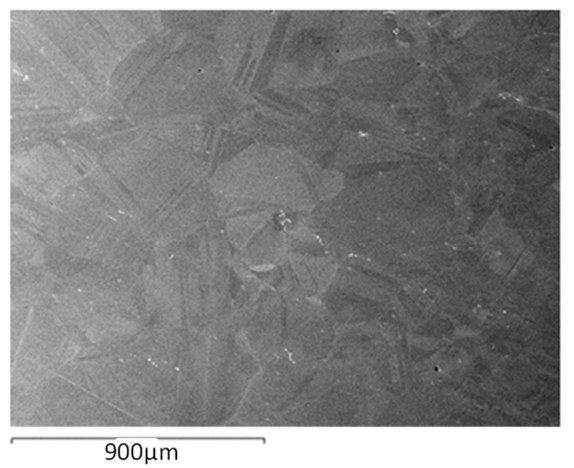

Figure 10. Microstructure and surface defects of CADCAM milled samples: (a) machining marks and (b) equiaxial grains with twins inside.

As seen in Figure 10b, CADCAM milled samples presented a highly homogeneous microstructure characterized by the presence of uniform equiaxial grains with large quantities of twins inside. This equiaxial microstructure revealed that the material has been subjected to prior annealing heat treatment, which was realized in order to remove the internal stress generated during the material's production. Additionally, the presence of twins inside the crystalline grains might be related to the residual stresses generated during the CADCAM milling process. The as-received material has been submitted to cold worked, and consequently the material does not present porosity, voids or cracks which could decrease the mechanical properties. In view of the results, the microstructure of CADCAM milled samples mainly depended on the initial microstructure of the as-received pre-manufactured block.

In Figure 11a, the surface of a sample obtained by laser sintering can be observed. The welding seams produced along the sintering path described by the laser beam are clearly identified. Besides, the surface analysis also revealed the presence of several porous with many particles inside, as seen in Figure 11b. Furthermore, an in-depth analysis of this porosity has shown a clear alignment between pores. These defects have a negative influence on the mechanical properties of laser-sintered components, which can lead to significant anisotropic mechanical behavior.

a)

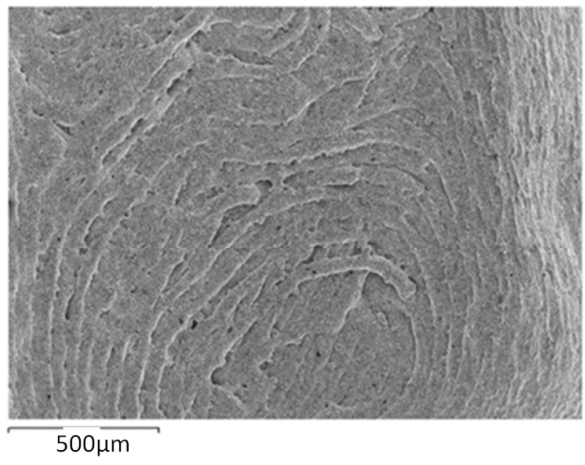

b)

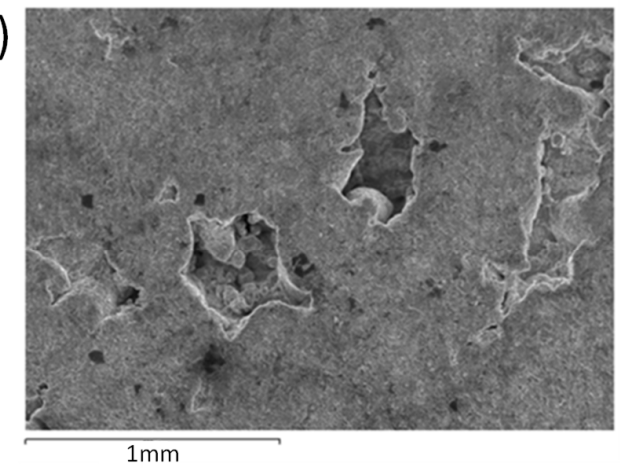

Figure 11. Surface defects of laser-sintered samples observed by SEM: (a) welding seams produced along the sintering path, and (b) Aligned microporosity with particles inside.

Microstructures of casted samples are shown in Figure 12a, in which typical dendritic morpholgy predominated. This color gardient in greyscale was due to the chemical composition differences (chemical segregation) between diferent phases as a function of $\mathrm{Cr}$ and $\mathrm{Co}$ contents. The white second phase consisted of intermetallic precipitates very rich in $\mathrm{W}$ and $\mathrm{Co}$, which were located along the interdendritic grain boundaries. Figure $12 \mathrm{~b}$ shows SEM micrograph at high magnification, in which a surface pore with a crack inside has also been observed. The stress state in this defective area is high due to the residual stress accumulated by volume contraction (volumetric shrinkage) during the 
transformation from liquid to solid. This stress was higher than the material strength and produced a crack.

a)

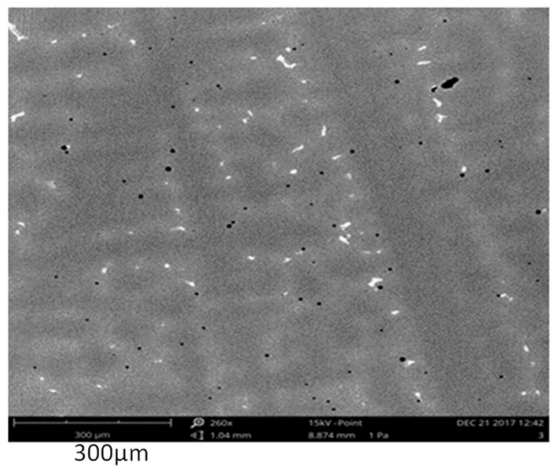

b)

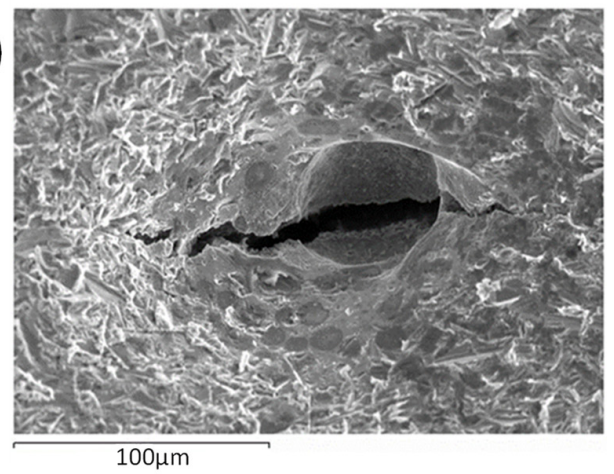

Figure 12. Microstructure and defects of Casted samples. (a) Porous and precipitates. (b) Porous with crack due to the volume contraction.

In the microstructure of the laser sintered samples, small precipitates which gave hardness to the material were observed. The size of these precipitates is fine and the quantities are lower than the casted samples. Figure 13 shows these white precipitates with their corresponding EDS-microanalysis which confirm precipitates formed by wolfram and Niobium. The black points are porosity.
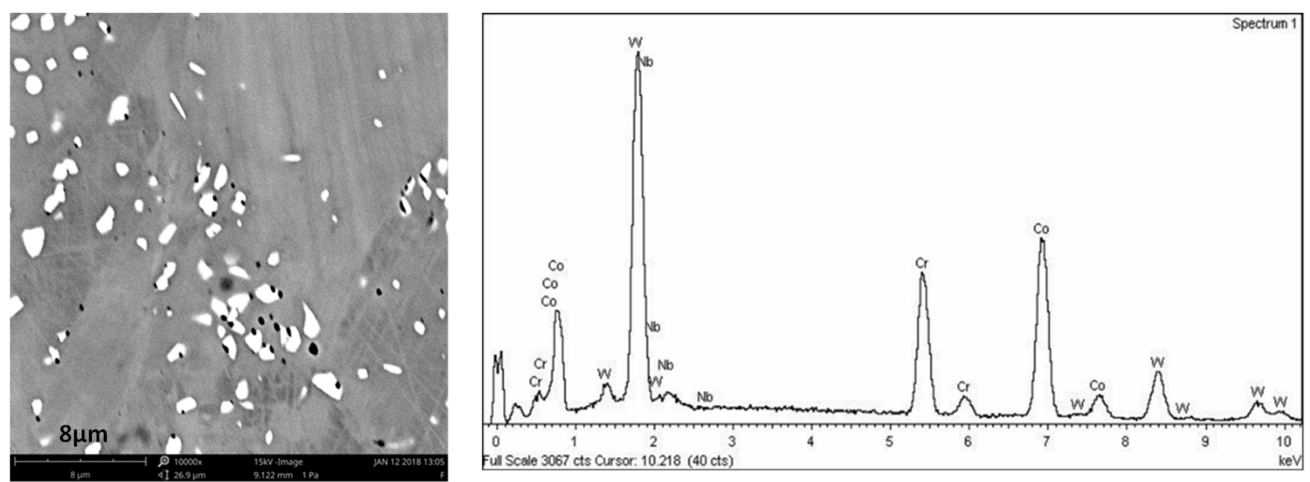

Figure 13. Microstructure of laser-sintered samples with white precipitates and EDS microanalysis of these precipitates.

A group of representative SEM images of the fractured surfaces after the 3-point bending test are shown in Figure 14. SEM fractographical analysis of CADCAM milled samples clearly showed a predominantly brittle fracture behavior, with facetted planes without plastic strain, as seen in (Figure 14a,b). Deep farrows have also been observed in fractured surfaces of CADCAM milled samples, as well as the presence of a large number of transverse and longitudinal secondary cracks that were randomly distributed. 
a)

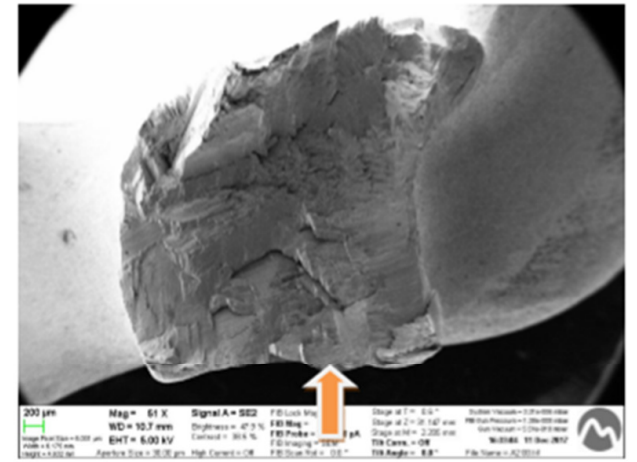

c)

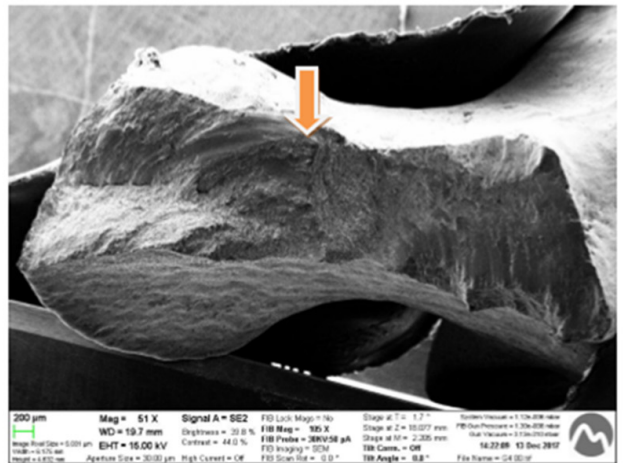

e)

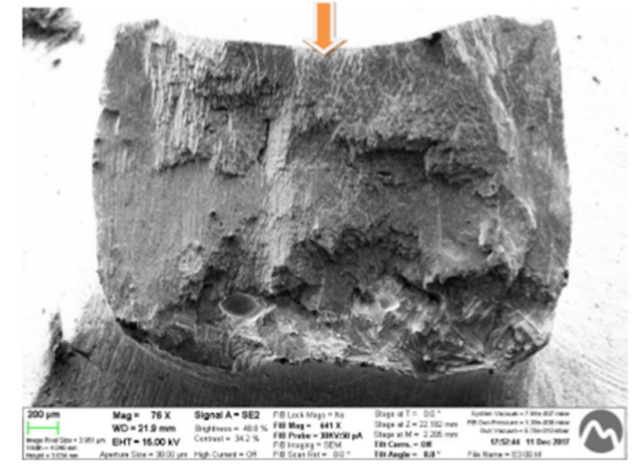

b)

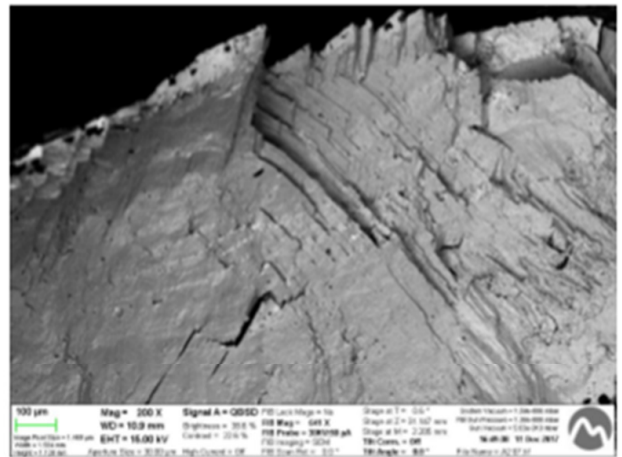

d)

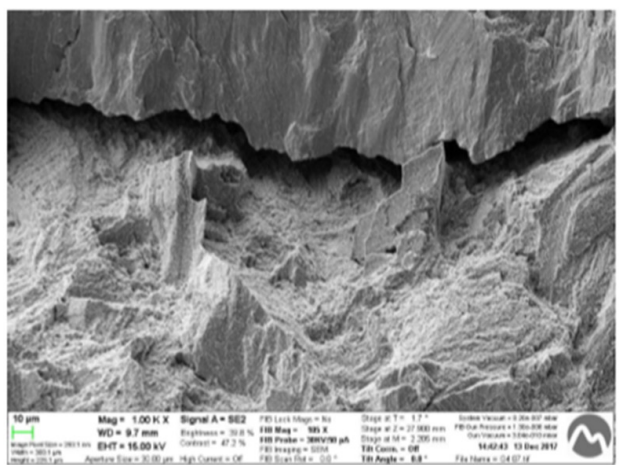

f)

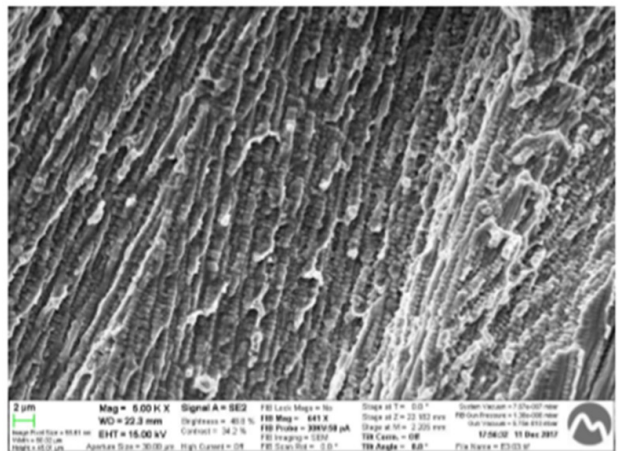

Figure 14. Fractographic images of mechanical tested samples. CADCAM milled samples with brittle fracture $(\mathbf{a}, \mathbf{b})$. Laser sintered samples with mixed fracture $(\mathbf{c}, \mathbf{d})$. Casted samples with detail of crack propagation with preferential directionality $(\mathbf{e}, \mathbf{f})$.

Fractographic images of laser sintered samples showed mixed-fracture behavior, with some areas with brittle fracture and others with plastic deformation, as seen in Figure 14c,d. A non-linear type of crack propagation has been observed in laser-sintered fractured surfaces. Consequently, the fracture of laser-sintered samples was sensible to microstructure, very similar to that seen with casted samples.

Fractographic observations of casted samples (Figure 14e,f) presented a clear directionality of the fracture. The fractures were also sensitive to the microstructure (if singular, the fracture was also sensitive to the microstructure). The crack propagation followed a dendritic orientation, as seen in Figure 13e,f.

\section{Discussion}

On the basis of the results obtained in marginal gap determination, the CADCAM manufacturing method using programmable 5-axis automatic milling machine presented the highest level of accuracy in comparison to the other processes. This would be due to the ability to reproducing a 3D item from a 3D-CAD file. In contrast, traditional casting process by the lost-wax method showed the lowest 
accuracy in terms of marginal fit. It is well known that the influence of both ability and experience of the laboratory technician to elaborate dental restorations has a crucial role in the quality of the end product. We should also take into consideration the fact that the defects caused by solidification (porous, volume contraction, chemical segregations, etc.) are important disadvantages for the fidelity of the prosthesis' dimensions. The laser-sintering process is somewhere in the middle, possessing the advantages and limitations of both techniques. This manufacturing technique is also fully automated, but does not provide the accuracy levels achieved by CADCAM milling [55,63].

Cutting instruments (fine and sharp tools) are essential to achieving accuracy with the CADCAM Process. Nevertheless, this method also has some disadvantages such as material wastage, and wear, tear, and damage of the cutting tools during milling which leads to an increase in production costs. Laser sintering can produce samples with great accuracy of complex geometries where fine details are important $[64,65]$. However, porosity and chemical composition segregation resulting from the use of high melting temperatures are their main disadvantage. Regarding the final structures produced, inner porosity and geometric distortion levels produced by laser sintering were lower than the casting technique. Sometimes the unacceptable distortion produced unacceptable discrepancies, which were fixed through cutting and welding [65].

Base materials used as raw materials in CADCAM milling processes are free of pores and flaws developed due to casting $[66,67]$. The as-received materials have been cold-worked and treated with an annealing-heat treatment in order to eliminate the residual stresses, as well as increasing the density of the material through the removal of production defects. Consequently, CADCAM milled samples avoid the presence of defects associated with solidification mechanisms of Co-Cr alloys [68-71]. The absence of casting defects, together with the use of excellent cutting procedures, produce both the highest levels of accuracy and the best surface finish, as can be observed by Scanning Electron Microcopy and quantified by roughness values with statistically significant differences between each method used.

Microhardness results showed that laser-sintered microstructures presented higher hardness values $(473 \pm 25)$ than casted samples $(390 \pm 15)$, whereas the lowest value corresponded to CADCAM milled samples $(356 \pm 20)$. These results may be attributed to the finer distribution of the dispersed phase. It is well known that with both finer and dispersed phase, the material presents higher hardness due to increased obstacles for the mobility of dislocations. The casted samples showed the presence of this second dispersed phase in their microstructure (Figure 13) but the precipitates were bigger in size and presented in a lower quantity. This fact favors the dislocation mobility and hardness decrease. Besides, the microstructural grain size obtained by casting were higher than that produced by laser sintering due to the lower cooling process [68]. In addition, the presence of residual stresses during sintering is another possible explanation for the increased hardness [72-74]. CADCAM samples did not present a dispersed second phase in their microstructure with the exception of a few isolated clusters of precipitates. The material did not present residual stress due to the annealing treatment, which relaxed the stresses induced by milling

Takaichi et al. [65] showed that microstructure, porosity and mechanical properties are dependent not only on the alloy but also on the operational parameters. The addition of $\mathrm{W}$ and Mo in the chemical composition of Co-Cr alloys produces stabilization of crystalline phases with hexagonal close-packed structures (hcp). It also strengthens the alloy through the formation of Mo and W carbide; however, recent studies have shown that the addition of $\mathrm{W}$ in $\mathrm{Co}-\mathrm{Cr}$ alloys could suppress the formation of brittle and undesirable sigma $(\sigma)$ phase, especially after the appropriate heat treatment.

In this study, the chemical composition was identical for each process. Therefore, it should be suggested that differences in the mechanical properties does not depend on elemental composition, but mainly depend on factors linked to the variations in the microstructure and defects related to the manufacturing methods used. Laser-sintering samples showed the highest values of hardness due to the dispersion of the fine precipitates, the presence of residual stresses and the small grain size. These properties are due to the manufacturing process. 
However, the maximum flexure load to fracture corresponded to CADCAM milled samples, which could be explained by the absence of extensive porosity. Porosity is undesirable, as it causes the mechanical properties to deteriorate and increases susceptibility to corrosion, such as crevice corrosion and pitting corrosion [28]. CADCAM milling provides structures with up to 100\% nominal density. However, laser-sintered samples do not exceed $92-95 \%$; these values are strongly dependent on the proper adjustment of operating conditions including laser power, temperatures, gas pressure, scan inter-spacing, as well as scan rate and thickness. The presence of a slight porosity and pore-free structures might explain the contradictory findings of the hardness in relation to the flexure load to fracture. Porosity is a well-known limitation of casted structures and is associated with the shrinkage of casting $[75,76]$ and the gross dendritic structure of $\mathrm{Co}-\mathrm{Cr}$ alloys during solidification, producing the lowest results for the flexural load to fracture.

The absence of porosity in manufactured structures produced by the CADCAM milling method has a positive effect on their mechanical properties as well. Several researchers are currently investigating how to implement this knowledge and technology to increase the efficiency of the laser-sintering process. Indeed, some researchers are focusing their efforts to assess the effect of the laser beam orientation on the laser sintered components. The effect of the laser beam inclination on the laser-sintered frameworks is still unknown to dentists and/or dental technicians. However, some studies indicate it is possible to produce structures with optimal orientations in order to provide maximum strengths in different directions due to the anisotropy $[77,78]$.

\section{Conclusions}

Based on the findings of this study, it can be considered that CADCAM milling process presents better marginal fit accuracy, surface quality (lower roughness) and higher flexure load to fracture as compared with laser sintering and casting methods. Casting and laser sintering showed porosity (inner and surface), residual stresses and chemical segregation in their microstructures, all of which play a key role in the mechanical properties. Casting and sintering conditions should be improved in order to enhance the microstructure and to avoid porosity to ensure optimal outcomes for clinical services.

Author Contributions: Conceptualization, M.P. and M.H.-C.; Data curation, A.B.V.; Formal analysis, M.M.; Funding acquisition, M.M. and E.R.; Investigation, R.P., M.P., M.M., M.H.-C., E.R. and F.J.G.; Methodology, R.P., A.B.V., E.R. and F.J.G.; Supervision, A.B.V. and M.H.-C.; Writing-original draft, F.J.G. All authors have read and agreed to the published version of the manuscript.

Funding: The work was supported by the Spanish government and the Ministry of Science and Innovation of Spain by the research project number RTI2018-098075-B-C21 and RTI2018-098075-B-C22, cofounded by the EU through the European Regional Development Funds (MINECO-FEDER, EU). Authors also acknowledge Generalitat de Catalunya for the funding through 2017SGR-1165 project.

Acknowledgments: In first place, the authors want to grateful to ARCHIMEDES company for the support in the research. This an example of the company which is involved in the research.

Conflicts of Interest: The authors declare no conflict of interest.

\section{References}

1. Mörmann, W.H.; Brandestini, M.; Lutz, F. The Cerec system: Computer-assisted preparation of direct ceramic inlays in 1 setting. Die Quintessenz 1987, 38, 457-470. [PubMed]

2. Sannino, G.; Germano, F.; Arcuri, L.; Bigelli, E.; Arcuri, C.; Barlattani, A. CEREC CAD/CAM Chairside System. Oral Implant. 2015, 7, 57-70.

3. Mangano, C.; Gandolfi, A.; Luongo, G.; Logozzo, S. Intraoral scanners in dentistry: A review of the current literature. BMC Oral Heal. 2017, 17, 149. [CrossRef] [PubMed]

4. Tapie, L.; Lebon, N.; Mawussi, B.; Chabouis, H.F.; Duret, F.; Attal, J.-P. Understanding dental CAD/CAM for restorations-The digital workflow from a mechanical engineering viewpoint. Int. J. Comput. Dent. 2015, 18, 21-44.

5. Tinschert, J.; Natt, G.; Hassenpflug, S.; Spiekermann, H. Status of current CAD/CAM technology in dental medicine. Int. J. Comput. Dent. 2004, 7, 25-45. 
6. Zimmermann, M.; Mehl, A.; Mörmann, W.H.; Reich, S. Intraoral scanning systems—A current overview. Int. J. Comput. Dent. 2015, 18, 101-129.

7. Rekow, E.D. Dental CAD-CAM Systems: What Is the State of the Art? J. Am. Dent. Assoc. 1991, 122, 42-48. [CrossRef]

8. Rekow, E.; Erdman, A.; Riley, D.; Klamecki, B. CAD/CAM for dental restorations-some of the curious challenges. IEEE Trans. Biomed. Eng. 1991, 38, 314-318. [CrossRef]

9. Roediger, M.; Schneider, L.; Rinke, S. Influence of Material Selection on the Marginal Accuracy of CAD/CAM-Fabricated Metal- and All-Ceramic Single Crown Copings. BioMed. Res. Int. 2018, 2018, 1-8. [CrossRef]

10. Sannino, G.; Gloria, F.; Schiavetti, R.; Ottria, L.; Barlattani, A. Dental Wings CAD/CAM system precision: An internal and marginal fit sperimental analisys. Oral Implant. 2010, 2, 11-20.

11. Mah, J.K.; Huang, J.C.; Choo, H. Practical Applications of Cone-Beam Computed Tomography in Orthodontics. J. Am. Dent. Assoc. 2010, 141, 7S-13S. [CrossRef] [PubMed]

12. Hong, J.-S.; Oh, K.-M.; Kim, B.-R.; Kim, Y.-J.; Park, Y.-H. Three-dimensional analysis of pharyngeal airway volume in adults with anterior position of the mandible. Am. J. Orthod. Dentofac. Orthop. 2011, 140, e161-e169. [CrossRef] [PubMed]

13. MacLeod, I.; Heath, N. Cone-beam computed tomography (CBCT) in dental practice. Dent. Update 2008, 35, 590-598. [CrossRef] [PubMed]

14. Scarfe, W.C.; Levin, M.D.; Gane, D.; Farman, A.G. Use of Cone Beam Computed Tomography in Endodontics. Int. J. Dent. 2010, 2009, 1-20. [CrossRef]

15. Quereshy, F.A.; Savell, T.A.; Palomo, J.M. Applications of Cone Beam Computed Tomography in the Practice of Oral and Maxillofacial Surgery. J. Oral Maxillofac. Surg. 2008, 66, 791-796. [CrossRef]

16. Swain, M.V.; Xue, J. State of the art of Micro-CT applications in dental research. Int. J. Oral Sci. 2009, 1, 177-188. [CrossRef]

17. Dong, G.; Dong, Q.; Liu, Y.; Lou, B.; Feng, J.; Wang, K.; Zhou, X.; Wu, H. High-resolution micro-CT scanning as an innovative tool for evaluating dental hard tissue development. J. Appl. Clin. Med. Phys. 2014, 15, 335-344. [CrossRef]

18. Ortorp, A.; Jonsson, D.; Mouhsen, A.; Von Steyern, P.V. The fit of cobalt-chromium three-unit fixed dental prostheses fabricated with four different techniques: A comparative in vitro study. Dent. Mater. 2011, 27, 356-363. [CrossRef]

19. Cho, S.-H.; Schaefer, O.; Thompson, G.A.; Guentsch, A. Comparison of accuracy and reproducibility of casts made by digital and conventional methods. J. Prosthet. Dent. 2015, 113, 310-315. [CrossRef]

20. Nawafleh, N.; Mack, F.; Evans, J.; Mackay, J.; Hatamleh, M.M. Accuracy and Reliability of Methods to Measure Marginal Adaptation of Crowns and FDPs: A Literature Review. J. Prosthodont. 2013, 22, 419-428. [CrossRef]

21. Koutsoukis, T.; Zinelis, S.; Eliades, G.; Al-Wazzan, K.; Al Rifaiy, M.; Al Jabbari, Y.S. Selective Laser Melting Technique of Co-Cr Dental Alloys: A Review of Structure and Properties and Comparative Analysis with Other Available Techniques. J. Prosthodont. 2015, 24, 303-312. [CrossRef] [PubMed]

22. Sofia, D.; Barletta, D.; Poletto, M. Laser sintering process of ceramic powders: The effect of particle size on the mechanical properties of sintered layers. Addit. Manuf. 2018, 23, 215-224. [CrossRef]

23. Sofia, D.; Granese, M.; Barletta, D.; Poletto, M. Laser Sintering of Unimodal Distributed Glass Powders of Different Size. Procedia Eng. 2015, 102, 749-758. [CrossRef]

24. Ferreira, T.J.; Vieira, M.T.; Costa, J.; Gato, P.T. Manufacturing Dental Implants using Powder Injection Molding. J. Orthod. Endod. 2016, 2, 1-21.

25. Ataee, A.; Li, Y.; Song, G.; Wen, C. Metal Scaffolds Processed by Electron Beam Melting for Biomedical Applications. In Metallic Foam Bone. Processing, Modification and Characterization and Properties; Elsevier: London, UK, 2017; pp. 83-110.

26. Suresh, G.; Narayana, L.; Kedar, M. Laser Engineered Net Shaping Process in Development of Medical Implants: An Overview. J. Adv. Res. Dynam. Control Syst. 2017, 9, 745-756.

27. Hero, H.; Syverud, M.; Gjonnes, J.; Horst, J. Ductility and structure of some cobalt-base dental casting alloys. Biomaterials 1984, 5, 201-208. [CrossRef] 
28. Qiu, J.; Yu, W.Q.; Zhang, F.Q.; Smales, R.J.; Zhang, Y.L.; Lu, C.H. Corrosion behaviour and surface analysis of a Co-Cr andtwo Ni-Cr dental alloys before and after simulated porcelainfiring. Eur. J. Oral Sci. 2011, 119, 94-101. [CrossRef]

29. Lewis, A.J. Radiographic evaluation of porosities in removable partial denture castings. J. Prosthet. Dent. 1978, 39, 278-281. [CrossRef]

30. Van Noort, R.; Lamb, D.J. A scanning electron microscope study of Co-Cr partial dentures fractured in service. J. Dent. 1984, 12, 122-126. [CrossRef]

31. Naert, I.; Van Der Donck, A.; Beckers, L. Precision of fit and clinical evaluation of all-ceramic full restorations followed between 0.5 and 5 years. J. Oral Rehabilitation 2005, 32, 51-57. [CrossRef]

32. Sorensen, S.E.; Larsen, I.B.; Jörgensen, K.D. Gingival and alveolar bone reaction to marginal fit of subgingival crown margins. Eur. J. Oral Sci. 1986, 94, 109-114. [CrossRef] [PubMed]

33. Felton, D.; Kanoy, B.; Bayne, S.; Wirthman, G. Effect of in vivo crown margin discrepancies on periodontal health. J. Prosthet. Dent. 1991, 65, 357-364. [CrossRef]

34. Jacobs, M.S.; Windeler, A.S. An investigation of dental luting cement solubility as a function of the marginal gap. J. Prosthet. Dent. 1991, 65, 357-364. [CrossRef]

35. Martins, L.M.; Lorenzoni, F.C.; De Melo, A.O.; Da Silva, L.M.; De Oliveira, J.L.G.; De Oliveira, P.C.G.; Bonfante, G. Internal fit of two all-ceramic systems and metal-ceramic crowns. J. Appl. Oral Sci. 2012, 20, 235-240. [CrossRef]

36. Kim, K.-B.; Kim, J.-H.; Kim, W.-C.; Kim, H.-Y.; Kim, J.-H. Evaluation of the marginal and internal gap of metal-ceramic crown fabricated with a selective laser sintering technology: Two- and three-dimensional replica techniques. J. Adv. Prosthodont. 2013, 5, 179-186. [CrossRef]

37. Christensen, G.J. Marginal fit of gold inlay castings. J. Prosthet. Dent. 1966, 16, 297-305. [CrossRef]

38. Baldissara, P.; Baldissara, S.; Roberto, S. Reliability of tactile perception using sharp and dull explorers in marginal opening identification. Int. J. Prosthodont. 1999, 11, 591-594.

39. Jahangiri, L.; Wahlers, C.; Hittelman, E.; Matheson, P. Assessment of sensitivity and specificity of clinical evaluation of cast restoration marginal accuracy compared to stereomicroscopy. J. Prosthet. Dent. 2005, 93, 138-142. [CrossRef]

40. Tan, P.L.; Gratton, D.G.; Holmes, D.C.; Diaz-Arnold, A.M. An In Vitro Comparison of Vertical Marginal Gaps of CADCAM Titanium and Conventional Cast Restorations. J. Prosthodont. 2008, 17, 378-383. [CrossRef]

41. Leong, D.; Chai, J.; Lautenschlager, E.; Gilbert, J. Marginal fit of machine-milled titanium and cast titanium single crowns. Int. J. Prosthodont. 1994, 7, 440-447.

42. Martínez-Rus, F.; Ferreiroa, A.; Ozcan, M.; Pradies, G. Marginal discrepancy of monolithic and veneered all-ceramic crowns on titanium and zirconia implant abutments before and after adhesive cementation: A scanning electron microscopy analysis. Int. J. Oral Maxillofac. Implant. 2013, 28, 480-487. [CrossRef] [PubMed]

43. Nedelcu, R.; Olsson, P.; Nyström, I.; Thor, A. Finish line distinctness and accuracy in 7 intraoral scanners versus conventional impression: An in vitro descriptive comparison. BMC Oral Heal. 2018, 18, 27. [CrossRef] [PubMed]

44. Aldegheishem, A.; Ioannidis, G.; Att, W.; Petridis, H. Success and Survival of Various Types of All-Ceramic Single Crowns: A Critical Review and Analysis of Studies with a Mean Follow-Up of 5 Years or Longer. Int. J. Prosthodont. 2017, 30, 168-181. [CrossRef] [PubMed]

45. Rinke, S.; Fornefett, D.; Gersdor, N.; Lange, K.; Roediger, M. Multifactorial analysis of the impact of different manufacturing processes on the marginal t of zirconia copings. Dent. Mater. 2012, 31, 601-609. [CrossRef]

46. McLean, J.W.; von Fraunhofer, J.A. E Estimation of cement $\mathrm{lm}$ thickness by an in vivo technique. Br. Dent. J. 1971, 131, 107-111. [CrossRef]

47. Contrepois, M.; Soenen, A.; Bartala, M.; Laviole, O. Marginal adaptation of ceramic crowns: A systematic review. J. Prosthet. Dent. 2013, 110, 447-454. [CrossRef]

48. Song, T.-J.; Kwon, T.-K.; Yang, J.-H.; Han, J.-S.; Lee, J.-B.; Kim, S.-H.; Yeo, I.L. Marginal fit of anterior 3-unit fixed partial zirconia restorations using different CAD/CAM systems. J. Adv. Prosthodont. 2013, 5, 219-225. [CrossRef]

49. Lövgren, N.; Roxner, R.; Klemendz, S.; Larsson, C. Effect of production method on surface roughness, marginal and internal fit, and retention of cobalt-chromium single crowns. J. Prosthet. Dent. 2016, 118, 95-101. [CrossRef] 
50. Hama Suleiman, S.; Vult von Steyern, P. Fracture strength of porcelain fused to metal crowns made of cast, milled or laser-sintered cobalt-chromium. Acta Odontol. Scand 2013, 71, 1280-1289. [CrossRef]

51. Reclaru, L.; Ardelean, L.; Rusu, L.C.; Sinescu, C. Co-Cr Material Selection in Prosthetic Restoration: Laser Sintering Technology. Solid State Phenom. 2012, 188, 412-415. [CrossRef]

52. Boitelle, P.; Mawussi, B.; Tapie, L.; Fromentin, O. A systematic review of CAD/CAM fit restoration evaluations. J. Oral Rehabilitation 2014, 41, 853-874. [CrossRef] [PubMed]

53. Wiskott, H.W.; Belser, U.C.; Scherrer, S.S. The effect of film thickness and surface texture on the resistance of cemented extra coronal restorations to lateral fatigue loading. Int. J. Prosthodont. 1999, 12, 255-262. [PubMed]

54. Juntavee, N.; Millstein, P.L. Effect of surface roughness and cement space on crown retention. J. Prosthet. Dent. 1992, 68, 482-486. [CrossRef]

55. Castillo-Oyagüe, R.; Osorio, R.; Osorio, E.; Sánchez-Aguilera, F.; Toledano, M. The effect of surface treatments on the microroughness of laser-sintered and vacuum-cast base metal alloys for dental prosthetic frameworks. Microsc. Res. Tech. 2012, 75, 1206-1212. [CrossRef] [PubMed]

56. Han, X.; Sawada, T.; Schille, C.; Schweizer, E.; Scheideler, L.; Geis-Gerstorfer, J.; Rupp, F.; Spintzyk, S. Comparative Analysis of Mechanical Properties and Metal-Ceramic Bond Strength of Co-Cr Dental Alloy Fabricated by Different Manufacturing Processes. Materials 2018, 11, 1801. [CrossRef]

57. Holmes, J.R.; Bayne, S.C.; Holland, G.A.; Sulik, W.D. Considerations in measurement of marginal fit. J. Prosthet. Dent. 1989, 62, 405-408. [CrossRef]

58. Afify, A.; Haney, S.; Verrett, R.; Mansueto, M.; Cray, J.; Johnson, R. Marginal discrepancy of noble metal-ceramic fixed dental prosthesis frameworks fabricated by conventional and digital technologies. J. Prosthet. Dent. 2017, 119, 307.e1-307.e7. [CrossRef]

59. Kim, H.R.; Jang, S.-H.; Kim, Y.K.; Son, J.S.; Min, B.; Kim, K.-H.; Kwon, T.-Y. Microstructures and Mechanical Properties of Co-Cr Dental Alloys Fabricated by Three CAD/CAM-Based Processing Techniques. Materials 2016, 9, 596. [CrossRef]

60. Chan, C.-W.; Smith, G.; Lee, S. A Preliminary Study to Enhance the Tribological Performance of CoCrMo Alloy by Fibre Laser Remelting for Articular Joint Implant Applications. Lubricants 2018, 6, 24. [CrossRef]

61. Balla, V.K.; Bodhak, S.; Bose, S.; Bandyopadhyay, A. Porous tantalum structures for bone implants: Fabrication, mechanical and in vitro biological properties. Acta Biomater. 2010, 6, 3349-3359. [CrossRef]

62. Dikova, T. Bending fracture of $\mathrm{Co}-\mathrm{Cr}$ dental bridges, produced by additive technologies: Experimental investigation. Procedia Struct. Integr. 2018, 13, 461-468. [CrossRef]

63. Hong, M.-H.; Min, B.; Kwon, T.-Y. Fabricating High-Quality 3D-Printed Alloys for Dental Applications. Appl. Sci. 2017, 7, 710. [CrossRef]

64. Sing, S.L.; An, J.; Yeong, W.Y.; Wiria, F.E. Laser and electron-beam powder-bed additive manufacturing of metallic implants: A review on processes, materials and designs. J. Orthop. Res. 2015, 34, 369-385. [CrossRef] [PubMed]

65. Takaichi, A.; Nakamoto, T.; Joko, N.; Nomura, N.; Tsutsumi, Y.; Migita, S.; Doi, H.; Kurosu, S.; Chiba, A.; Wakabayashi, N.; et al. Microstructures and mechanical properties of Co-29Cr-6Mo alloy fabricated by selective laser melting process for dental applications. J. Mech. Behav. Biomed. Mater. 2013, 21, 67-76. [CrossRef] [PubMed]

66. Shiomi, M.; Osakada, K.; Nakamura, K.; Yamashita, T.; Abe, F. Residual Stress within Metallic Model Made by Selective Laser Melting Process. CIRP Ann. 2004, 53, 195-198. [CrossRef]

67. Reclaru, L.; Susz, C.; Ardelean, L. Laser beam welding. Timisoara Med. J. 2010, 60, 86-89.

68. Muñoz, A.I.; Mischler, S. Effect of the environment on wear ranking and corrosion of biomedical CoCrMo alloys. J. Mater. Sci. Mater. Electron. 2011, 22, 437-450. [CrossRef]

69. Dharmar, S.; Rathnasamy, R.; Swaminathan, T. Radiographic and metallographic evaluation of porosity defects and grain structure of cast chromium cobalt removable partial dentures. J. Prosthet. Dent. 1993, 69, 369-373. [CrossRef]

70. Rodrigues, W.C.; Broilo, L.R.; Schaeffer, L.; Knörnschild, G.H.; Espinoza, F.R.M. Powder metallurgical processing of $\mathrm{Co}-28 \% \mathrm{Cr}-6 \% \mathrm{Mo}$ for dental implants: Physical, mechanical and electrochemical properties. Powder Technol. 2011, 206, 233-238. [CrossRef]

71. Jang, S.-H.; Lee, D.-H.; Ha, J.-Y.; Hanawa, T.; Kim, K.-H.; Kwon, T.-Y. Preliminary Evaluation of Mechanical Properties of Co-Cr Alloys Fabricated by Three New Manufacturing Processes. Int. J. Prosthodont. 2015, 28, 396-398. [CrossRef] 
72. Al Jabbari, Y.S.; Koutsoukis, T.; Barmpagadaki, X.; Zinelis, S. Metallurgical and interfacial characterization of PFM Co-Cr dental alloys fabricated via casting, milling or selective laser melting. Dent. Mater. 2014, 30, e79-e88. [CrossRef]

73. Simchi, A.; Pohl, H. Effects of laser sintering processing parameters on the microstructure and densification of iron powder. Mater. Sci. Eng. A 2003, 359, 119-128. [CrossRef]

74. Sailer, I.; Makarov, N.; Thoma, D.S.; Zwahlen, M.; Pjetursson, B.E. All-ceramic or metal-ceramic tooth-supported fixed dental prostheses (FDPs)? A systematic review of the survival and complication rates. Part I: Single crowns (SCs). Dent. Mater. 2015, 31, 603-623. [CrossRef] [PubMed]

75. Wolfart, S.; Wegner, S.M.; Al-Halabi, A.; Kern, M. Clinical evaluation of marginal fit of a new experimental all-ceramic system before and after cementation. Int. J. Prosthodont. 2004, 16, 58792.

76. Castillo-Oyagüe, R.; Sánchez-Turrión, A.; López-Lozano, J.F.; Suárez-García, M.J. Vertical discrepancy and microleakage of laser-sintered and vacuum-cast implant-supported structures luted with different cement types. J. Dent. 2012, 40, 123-130. [CrossRef] [PubMed]

77. Kruth, J.P.; Vandenbroucke, B.; Van Vaerenbergh, J.; Mercelis, P. Benchmarking of Different SLS/SLM Processes as Rapid Manufacturing Techniques. In Proceedings of the International Conference Polymers \& Moulds Innovations (PMI), Gent, Belgium, 20-24 April 2005; p. 525. Available online: http://doc.utwente.nl/52902/ (accessed on 20 May 2013).

78. Ucar, Y.; Akova, T.; Akyil, M.S.; A Brantley, W. Internal fit evaluation of crowns prepared using a new dental crown fabrication technique: Laser-sintered Co-Cr crowns. J. Prosthet. Dent. 2009, 102, 253-259. [CrossRef]

(C) 2020 by the authors. Licensee MDPI, Basel, Switzerland. This article is an open access article distributed under the terms and conditions of the Creative Commons Attribution (CC BY) license (http://creativecommons.org/licenses/by/4.0/). 